\title{
EVALUASI INTERNAL PROGRAM STUDI MENGGUNAKAN METODE NAÏVE BAYES CLASSIFIER (NBC)
}

\author{
Yoseph Pius Kurniawan Kelen ${ }^{1}$ \\ ${ }^{1)}$ Universitas Timor-Kefamenanu \\ ${ }^{1)}$ e-mail: yosepkelen@gmail.com
}

\begin{abstract}
The Development of department and study program can not be seperated by its internal factors which is influenced number of candidate of students it self direct or indirectly. In this case we need a method to know the condition in each internal variables that will be evaluated in the department itself.

NBC method is kind of simple Bayesian Network that comes with assume statement that all features are similar one with another. $\mathrm{Nbc}$ shows the great work completely in accuracy and failed classification level. NBC could predict some assume for prediction needs.

This research generally made to use for evaluating department and study program internarly by clasifying some variables which can influence to know about the condition of the deprtment and the study program itself. This is also one $8 \mathrm{f}$ best strategy to develope number of new cndidte of students and this method will shows about the study program to the new candidate of students.
\end{abstract}

Keywords : NBC,Naïve Bayes Clasification, Study Program Evaluating. 


\section{Pendahuluan}

Faktor yang mempengaruhi perkembangan tiap program studi baik secara langsung maupun tak langsung dapat mempengaruh jumlah mahasiswa baru, faktor-faktor utama tersebut diantaranya jumlah dosen, jumlah mahasiswa serta ketersediaan sarana prasarana (Vallejos,2012). Metode NBC merupakan bentuk sederhana dari sebuah Bayesian network yang merupakan salah satu metode data mining.NBC mempunyai keunggulan akurasi dan minimnya tingkat kesalahan klasifikasi (Koc,2012). NBC mempunyai kemampuan inferensial dan keputusan yang baik sehingga memberikan fleksibilitas dalam penerapan untuk menganalisis faktor yang mempengaruhi sistem ( $\mathrm{Li}, 2013)$.

Keputusan perlu dilakukan oleh pengambil keputusan dengan preferensi tertentu berdasarkan informasi dan pengetahuan. Kinerja NBC kompetitif dalam proses klasifikasi walaupun menggunakan asumsi atribut yang independen (tidak ada kaitan antar atribut). Metode NBC yang digunakan pada penelitian ini untuk mengevaluasi program studi sehingga dapat membantu meningkatkan kinerja fakultas khususnya Program Studi.

\section{Kerangka Teori}

\section{a. Naïve Bayes Classifier (NBC)}

Naïve Bayesian Classifier mengansumsikan bahwa keberadaan sebuah atribut (variabel) tidak ada kaitannya dengan beradaan atribut yang lain (Abidin., 2012).

$$
P(H \mid X)=\frac{P(X \mid H) P(H)}{P(X)}
$$

Keterangan :

$X \quad=$ data sampel dengan klas (label) yang tidak diketahui

$H \quad=$ hipotesa bahwa $X$ adalah data dengan klas (label)

$P(H) \quad=$ peluang dari hipotesa $\mathrm{H}$ (likelihood)

$P(X) \quad=$ peluang data sampel yang diamati (evidence)

$P(X \mid H)=$ peluang data sampel $X$, bila diasumsikan bahwa hipotesa $\mathrm{H}$ benar (prior)

Dalam NBC H adalah posterior dan X adalah prior. Prior adalah pengetahuan tentang karakteristik suatu parameter, sedangkan posterior adalah karakteristik yang diduga pada kejadian yang akan dating ( $\mathrm{Li}, 2012)$. NBC menyediakan mekanisme merevisi atau memperbarui pengetahuan sebelumnya dengan data baru untuk menghasilkan laporan probabilitas posterior tentang parameter yang tidak diketahui atau berdasarkan hipotesis (Chu, 2011).

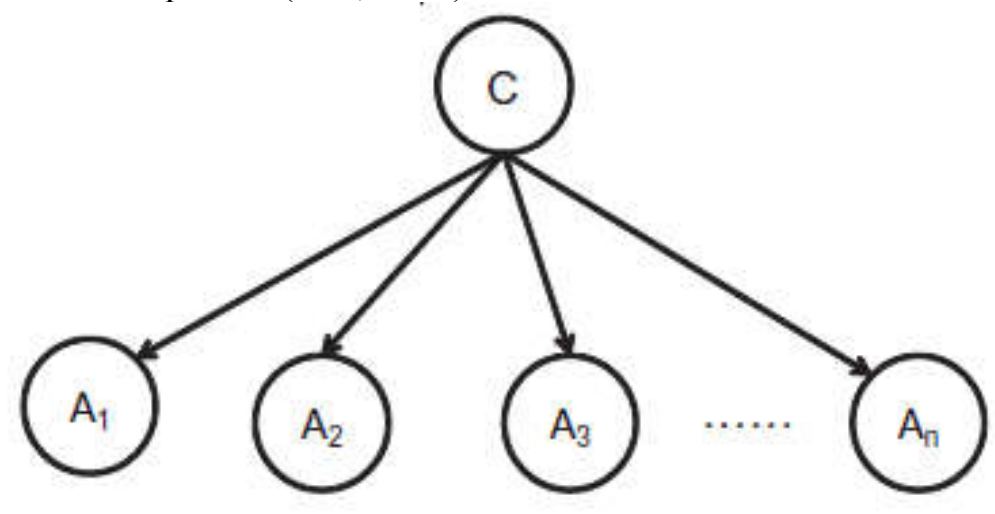

Gambar 2.1. Struktur Naïve Bayes Classifier

Sebuah NBC adalah classifier probabilistik sederhana berdasarkan pada penerapan teorema Bayes dengan asusmsi bebas. Variabel acak yang melambangkan 
kelas turunan dan X menjadi vektor variabel acak yang menunjukkan nilai-nilai atribut yang diamati (Soria, 2011).

Formulasi NBC untuk klasifikasi adalah :

$$
P(Y \mid X)=\frac{P(Y) \Pi_{i=1}^{q} P\left(X_{\mathrm{i}} \mid Y\right)}{P(X)}
$$

Keterangan :

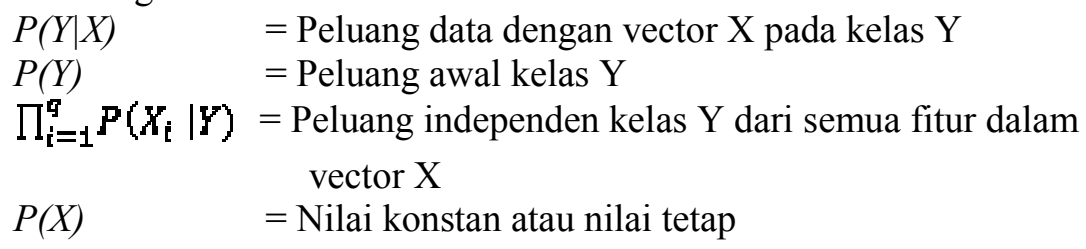

Berdasarkan nilai $\mathrm{P}(\mathrm{X})$ yang memang telah bernilai tetap maka nantinya hanya menghitung pada bagian $\boldsymbol{P}(Y) \prod_{i=1}^{\boldsymbol{T}} \boldsymbol{P}\left(X_{i} \mid Y\right)$. Untuk peluang independen $\prod_{i=1}^{q} P\left(X_{i} \mid Y\right)$ adalah pengaruh semua atribut dari data terhadap kelas $Y$ yang dinitasikan seperti dibawah ini :

$$
P(X \mid Y=y)=\prod_{i=1}^{q} P\left(X_{i} \mid Y=y\right)
$$

Distribusi Gaussian biasanya dipilih untuk merepresentasikan peluang bersyarat dari atribut kontinyu pada sebuah kelas $\mathrm{P}\left(\mathrm{X}_{\mathrm{i}} \mid \mathrm{Y}\right)$, sedangkan distribusi Gaussian dikarakteristikan dengan dua parameter yaitu : mean $(\mu)$ dan varian $\left(\sigma^{2}\right)$. Untuk setiap kelas $\mathrm{y}_{\mathrm{j}}$, peluang bersyarat kelas $\mathrm{y}_{\mathrm{j}}$, untuk atribut $\mathrm{X}_{\mathrm{i}}$ adalah :

$$
P\left(X_{i}=x \mid Y=y_{j}\right) x=\frac{1}{\sqrt{2 \pi 0 i j}} \exp ^{\frac{\left(x i-\mu i j^{2}\right.}{2 \sigma j^{2}}}
$$

\section{b. Klasifikasi}

Proses penting yang dilakukan saat melakukan klasifikasi yang pertama adalah learning yaitu proses pembelajaran menggunakan training set. dan yang kedua adalah proses testing yaitu menguji model menggunakan data testing.

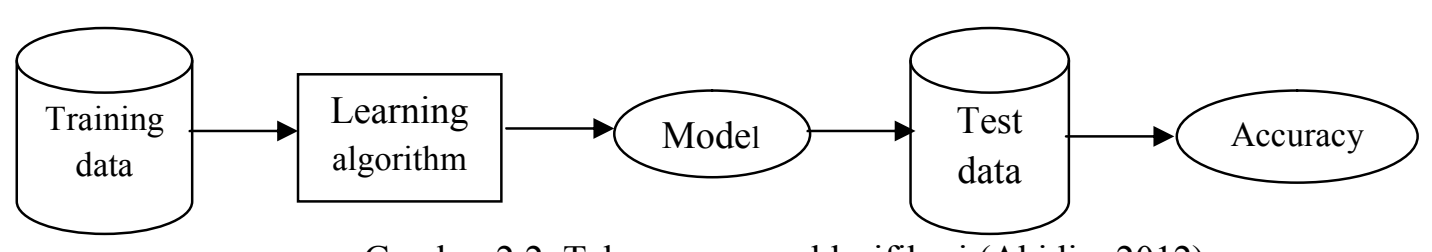

Gambar 2.2. Tahapan proses klasifikasi (Abidin, 2012)

Confusion matrix adalah matrik yang berbentuk $2 \times 2$ untuk mendapatkan hasil klasifikasi dengan tepat, tiap kelas yang diprediksi mempunyai kemungkinan keluaran yang berbeda-beda seperti diantaranya true positives (TP) yaitu menunjukkan ketepatan klasifikasi dan false positive (FP) adalah jika nilai aslinya dan nilai yang diprediksi berbeda. Tabel confusion matrix seperti berikut ini :

Tabel 2.2. confusion matrix

\begin{tabular}{|l|l|l|c|}
\hline & & \multicolumn{2}{|c|}{ Predicted Class } \\
\hline \multirow{3}{*}{ Actual Class } & & \multicolumn{1}{|c|}{$\mathrm{C} 1$} & $\mathrm{C} 2$ \\
\cline { 2 - 4 } & $\mathrm{C} 1$ & True Positive & False negative \\
& $\mathrm{C} 2$ & False positive & True negatives \\
\hline
\end{tabular}


Akurasi dapat didefenisikan sebagai berikut

$$
\text { Akurasi }=\frac{\text { jumlah predikgi benar }}{\text { jumlah total predi lrai }}
$$

\section{Metodologi}

Pengumpulan data; di tahap ini adalah mengumpulkan semua data historis 2011-2016 di setiap prodi yaitu data penelitian, data dosen, data pegawai, data mahasiswa, data alumni, data sarana prasarana (kelas), data sarana prasarana (laboratorium), dan data beasiswa. Data yang menjadi variabel utama yang berpengaruh dan ketentuan penilaiannya adalah :

a. Publikasi : $\quad$ Sangat kurang $=0$

$\begin{array}{rll} & \text { Kurang } & =1-3 \\ & \text { Cukup } & =4-7 \\ & \text { Baik } & =8-10 \\ & \text { Sangat baik } & =11-15 \\ \text { b. Dosen : } & \text { S2 } & =\text { baik } \\ & \text { S3 } & =\text { Sangat Baik } \\ \text { c. Pegawai: } & \text { Honorer } & =\text { Kurang } \\ & \text { PNS } & =\text { Baik } \\ \text { d. Mahasiswa : } & \text { Sangat Kurang } & =0-5 \\ & \text { Kurang } & =6-10 \\ & \text { Cukup } & =11-20 \\ & \text { Baik } & =21-40 \\ \text { e. Alumni : } & \text { Sangat Baik } & =41-70 \\ & \text { Sangat Kurang } & =0-5 \\ & \text { Kurang } & =6-10 \\ & \text { Cukup } & =11-20 \\ & \text { Baik } & =21-40 \\ \text { f. } \quad \text { Kelas : Cukup } & \text { Sangat Baik } & =41-70 \\ & \text { Baik } & =2 \\ \text { g. Laboratorium : } & \text { Cukup } & =\text { tidak terawat } \\ \text { Baik } & =\text { terawat } \\ \text { h. Seminar : } \quad \text { Sangat kurang } & =0 \\ & \text { Kurang } & =1-5 \\ & \text { Cukup } & =6-10 \\ & \text { Baik } & =11-15 \\ & \text { Sangat Baik } & =16-20 \\ & & \end{array}$

Berikut ini alur proses NBC yaitu pada Gambar 3.1: 

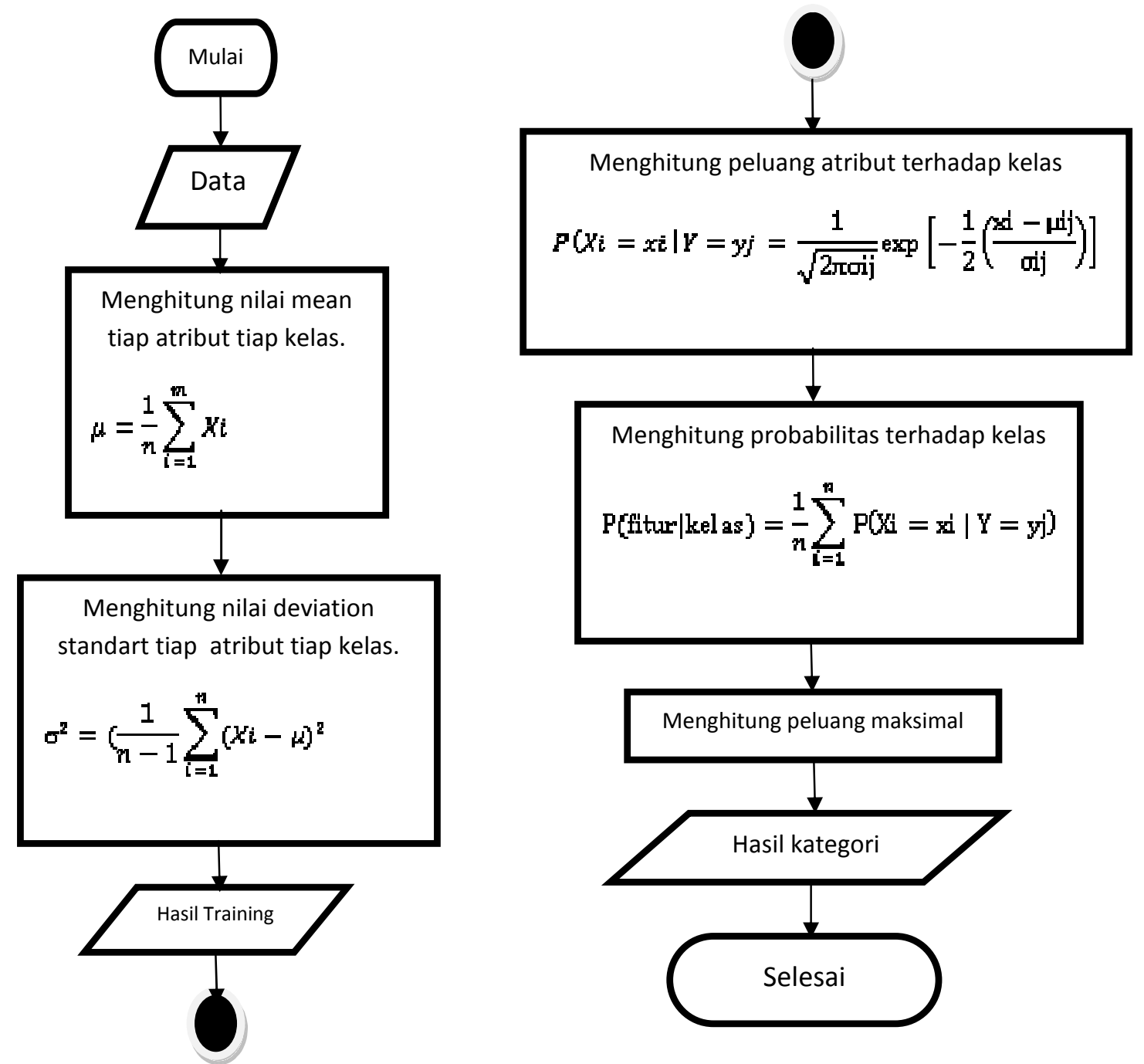

Gambar 3.1 Alur proses NBC

\section{Hasil dan Pembahasan}

\subsubsection{Pengujian Metode Nä̈ve Bayes Classifier}

Sesuai dengan data terdapat pada program studi Ilmu Komputer Universitas Nusa Cendana, untuk data testing sesuai input sebelumnya menggunakan tahun 2016. Untuk data training dari tahun 2011 sampai 2015 sesuai data pada sistem terdapat pada tabel berikut :

Tabel 4.1. Data training prodi Ilmu Komputer

\begin{tabular}{|c|c|c|c|c|c|c|c|c|c|c|}
\hline Prodi & Tahun & Publikasi & Dosen & Pegawai & Mahasiswa & Alumni & Kelas & Lab. & Seminar & $\begin{array}{c}\text { Status } \\
\text { Prodi }\end{array}$ \\
\hline Ilkom & 2011 & 0 & S3 & PNS & 12 & 8 & 1 & Terawat & 2 & Cukup \\
\hline Ilkom & 2012 & 8 & S3 & PNS & 36 & 21 & 1 & Terawat & 18 & Baik \\
\hline Ilkom & 2013 & 7 & S3 & PNS & 45 & 16 & 2 & Terawat & 6 & Baik \\
\hline Ilkom & 2014 & 16 & S3 & PNS & 61 & 24 & 2 & Terawat & 15 & Baik \\
\hline Ilkom & 2015 & 3 & S3 & PNS & 69 & 70 & 2 & Terawat & 0 & Cukup \\
\hline Ilkom & 2016 & 18 & S3 & PNS & 49 & 45 & 2 & Terawat & 11 & Baik \\
\hline
\end{tabular}


Tabel 4.2 hasil data testing

\begin{tabular}{|c|c|c|c|c|c|c|c|c|c|c|}
\hline Prodi & Tahun & Publikasi & Dosen & Pegawai & Mahasiswa & Alumni & Kelas & Lab & Seminar & $\begin{array}{c}\text { Status } \\
\text { Prodi }\end{array}$ \\
\hline Ilkom & 2016 & 11 & S3 & PNS & 55 & 45 & 2 & Terawat & 8 & Baik \\
\hline
\end{tabular}

\section{Penutup}

Pada penelitian evaluasi internal program studi menggunakan naïve bayes classifier ini dapat disimpulkan :

1. Penggunaan metode NBC untuk evaluasi internal program studi dapat mengevaluasi setiap atribut yang berpengaruh pada setiap program studi, sehingga dapat diketahui keadaan atau status masing-masing program studi.

2. Evaluasi internal program studi dengan menggunakan metode NBC ini dapat menjadi media untuk calon mahasiswa baru mengetahui keadaan program studi yang akan dipilih nantinya.

3. Evaluasi ini dapat menghasilkan suatu klasifikasi yang tepat untuk menjadi bahan pertimbangan untuk pengambilan keputusan pimpinan dalam merekomendasikan kebutuhan untuk setiap program studi sehingga dapat menciptakan fakultas menjadi lebih baik lagi.

4. Penggunaan NBC cukup efektif digunakan pada data program studi karena mempunyai nilai akurasi mendekati $100 \%$.

\subsection{Saran}

Saran yang dapat diberikan pada penelitian selanjutnya agar penelitian ini dapat diperbaiki atau dikembangkan adalah :

1. Pada penelitian ini menggunakan delapan data (atribut) yang dianggap paling berpengaruh, pada penelitian selanjutnya dapat meningkatkan jumlah pemakaian data.

2. Penelitian ini menggunakan metode naïve bayes classifier, untuk penelitian yang berhubungan dengan klasifikasi dapat menggunakan metode lainnya dan dapat dibandingkan nilai akurasinya dengan penggunaan NBC.

\section{DAFTAR PUSTAKA}

Chu P., S., dan Zhao X., 2011, Bayesian analysis for extreme climatic events: A review, Hawaii. Journal of Atmospheric Research 102. 243-262

Koc L., Mazzuchi T., dan Sarkani S., 2012, A network intrusion detection system based on a Hidden Naïve Bayes multiclass classifier, USA. Journal of Expert Systems with Applications 39. 13492-13500

Li D., Yang H., Z., dan Liang X., F., 2013, Prediction analysis of a wastewater treatment system using a Bayesian network, China. Journal of Environmental Modelling \& Software 40. 140-150

Li G., dan Shi J., 2012, Applications of Bayesian methods in wind energy conversion systems, USA. Journal of Renewable Energy 43. 1-8

Soria D., Garibaldi Jonathan M., Ambrogi F., Biganzoli Elia M., Ellis Ian O., 2011, A 'nonparametric' version of the naive Bayes classifier. Journal of Knowledge-Based Systems 24. $775-784$

Vallejos M., Alvarado Jesus M., dan Puente A., 2012, College performance prediction test, Spain. Journal of Procedia - Social and Behavioral Sciences 31. 846 - 851. 